\title{
Assessment of basic life support skills among medical doctors and technicians in Belgrade emergency medical services
}

\author{
GORAN ČOLAKOVIĆ, SLAĐANA ANĐELIĆ, IVANA STEFANOVIĆ, SNEŽANA \\ BOGUNOVIĆ, NADA EMIŠ-VANDLIK, SRĐAN STOJANOVIĆ
}

Belgrade Emergency Medical Services, Serbia

Correspoding author:

Slađana Anđelić

Belgrade Emergency Medical Services

Franše d'Eperea 5, 11000 Belgrade, Serbia

Phone: +381641245757

E-mail:novizivot94@gmail.com

\section{ABSTRACT}

Objective. Our aim was to assess BLS (basic life support) skills among medical doctors (MDs) and medical technicians (MTs) who work at Belgrade Emergency Medical Services (BEMS).

Methods. A prospective study was conducted between 28 September and 9 December, 2016. MDs (Group 1) and MTs (Group 2) attended an accredited course in BLS at BEMS. At the end of the course the participants were given a written test consisting of 20 questions (pass rate 65\%). The results were analyzed for each group i.e. profession (Group 1 and Group 2) according to the number of accurate and inaccurate answers to each question. In the end, a number of participants from each group, who answered all 20 questions correctly, were identified. The results obtained, by test analysis, demonstrated the participants' acquired BLS skills.

Results. The study involved 100 participants (50 in each group). All participants from Group 1 correctly answered questions number 1, 2, 3, 10, 13, 17 and 20. In Group 1 only two participants had three incorrect answers in the test. The largest number of incorrect answers was related to question number 16. Thirty-four participants in this group answered all questions correctly. All participants from Group 2 gave correct answers to questions number 2, 5, 9, 10 and 13. In Group 2, one participant had six incorrect answers and one participant had 5 incorrect answers. The largest number of incorrect answers was related to questions number 3 and 20. Nineteen participants from Group 2 answered all questions correctly. The rate of correct answers between Group 1 and Group 2 was $19.66: 18.91$ (0.75 difference).
Conclusion. The research showed a satisfactory level of knowledge in both groups. However, there is a statistically significant difference in the knowledge of MDs after the BLS course. The results obtained justify the ambitions that all healthcare professionals, regardless of their qualifications, should be trained in applying BLS, both at work and as eyewitnesses.

Key words: basic life support, knowledgel skills, doctors, medical technicians, emergency service

\section{INTRODUCTION}

Sudden cardiac arrest (SCA) is the leading cause of death in Europe. Around 1,000 SCAs are registered in Europe daily. (1) Recommendations for cardiopulmonary resuscitation (CPR) are a widely accepted approach to making reanimation as successful and safe as possible. An intervention that certainly helps patients survive SCA is fast and effective basic life support (BLS) by eyewitnesses of the event. According to current guidelines for CPR (1), all citizens should have some knowledge of BLS, both as laymen, i.e. people without formal medical education, and as healthcare professionals out of their workplace and without medical equipment, when in the role of eyewitnesses. Basic life support includes recognizing signs of SCA, obstruction of the airway by a foreign body and performance of CPR. Direct CPR can double or triple survival rates by implementing BLS skills. It is therefore crucial that healthcare workers in Emergency Medical Services (EMS), in the role of eyewitnesses and outside their workplace, start and implement BLS until the arrival of a medical team. In many countries, short-term or long- term successful experiences of introducing multi-day or one-day courses to their health institutions have been reported. (2) It has been proven that BLS training cannot be achieved only by reading or listening to theoretical concepts, but that practice is essential. The number of participants in the BLS course should be limited, in order to ensure equal and high quality acquisition of necessary knowledge and skills. (3)

The aim of this study was to assess basic life support knowledge among doctors and medical technicians of the Belgrade Emergency Medical Services (BEMS).

\section{METHODS}

A prospective study was conducted at the BEMS between 28 September and 9 December 2016. During this period, BEMS medical doctors - MDs (Group 1) and medical technicians - MTs (Group 2) attended an accredited course in BLS, according to a specially designed curriculum. The aim of theoretical instructions was to familiarize participants with 2015 BLS guidelines for adults.. Practical classes were conducted in small groups (4-6 participants). After the demonstration, participants attended workshops in which SCA was simulated and they practiced individual manual BLS skills on manikins (Little Anne ${ }^{m}$ CPR Manikin, Laerdal Corporation, Rorarco $\mathrm{GmbH}$, Vienna, Austria) in the presence of demonstrators. Those skills included compression of the sternum and artificial ventilation, relief of airway obstruction and coma position. At the end of the course, attendees took a written test consisting of 20 questions (Appendix1). The test is based on circling one or more answers offered. Each question carries 1 point. The maximum 
number of points is 20 . The results of correct and incorrect answers to each question were analyzed for each group in relation to profession (Group 1 and Group 2). Finally, the number of participants who answered all 20 questions correctly was determined for each group. The results obtained by analysis of the test demonstrate the participants' acquired knowledge in BLS. The results are shown in tables and graphs.

The answers to each question were entered into a database in SPSS (V.12.01, SPSS Inc., Chicago, IL, USA). Descriptive values of variables were expressed as averages and percentages. Mann-Whitney $U$ test was used to analyze the difference in accuracy rate for twenty questions during post-training evaluation between the two groups. A statistically highly significant level was defined as $\mathrm{p}<0.001$.

\section{RESULTS}

The study involved 100 respondents (50 BEMS medical doctors - Group 1 and 50 BEMS medical technicians - Group 2) who, after the BLS course, took a written test (65\% pass rate). Table 1 shows the number and percentage of correct and incorrect answers in Group 1 and Group 2 for each question in the test.

In the whole group, only two MDs had three incorrect answers in the test. The largest number of incorrect answers was related to question number 16 . Questions number 1, 2, 3, 10, 13, 17 and 20 were answered correctly by all MDs. The average number of correct answers in Group 1 was 19.66. In the whole group, one MT had 6 incorrect answers, and one had 5. The largest number of incorrect answers was related to questions number 3 and 20. Questions number 2, 5, 9, 10 and 13 were answered correctly by all MTs. The average number of correct answers in Group 2 was 18.91.

Thirty-four MDs and seventeen MTs answered all questions correctly. Ten MDs and 8 MTs had 1 incorrect answer; 4 MDs and 13 MTs had 2 incorrect answers; 2 MDs and 9 MTs had three incorrect answers. The number of MTs who answered four, five and six questions incorrectly was one in each case (Table 2).

Figure1 shows comparative values of total points scored by MDs and MTs ( $\mathrm{p}$ < 0.001).

\section{DISCUSSION}

There is an increasing number of courses worldwide and in the Republic of Serbia which are part of a continuous train-

Table 1. The number (N) and percentage (\%) of correct and incorrect answers in Group 1 and Group 2 for each question in the test

\begin{tabular}{|c|c|c|c|c|}
\hline & Doctors & & Medical tec & is / nurses \\
\hline Participants & 50 & & 50 & \\
\hline Question No & correct & incorrect & correct & incorrect \\
\hline & $\mathrm{N}-\%$ & $\mathrm{~N}-\%$ & $\mathrm{~N}-\%$ & $\mathrm{~N}-\%$ \\
\hline 1 & $50-100$ & $0-0$ & $44-88$ & $6-12$ \\
\hline 2 & $50-100$ & $0-0$ & $50-100$ & $0-0$ \\
\hline 3 & $50-100$ & $0-0$ & $35-70$ & $15-30$ \\
\hline 4 & $49-98$ & $1-2$ & $47-94$ & $3-6$ \\
\hline 5 & $49-98$ & $1-2$ & $50-100$ & $0-0$ \\
\hline 6 & $49-98$ & $1-2$ & $47-94$ & $3-6$ \\
\hline 7 & $49-98$ & $1-2$ & $48-96$ & $2-4$ \\
\hline 8 & $47-94$ & $3-6$ & $46-92$ & $4-8$ \\
\hline 9 & $49-98$ & $1-2$ & $50-100$ & $0-0$ \\
\hline 10 & $50-100$ & $0-0$ & $50-100$ & $0-0$ \\
\hline 11 & $49-98$ & $1-2$ & $38-76$ & $12-24$ \\
\hline 12 & $49-98$ & $1-2$ & $49-98$ & $1-1$ \\
\hline 13 & $50-100$ & $0-0$ & $50-100$ & $0-0$ \\
\hline 14 & $46-92$ & $4-8$ & $46-92$ & $4-8$ \\
\hline 15 & $47-94$ & $3-6$ & $47-94$ & $3-8$ \\
\hline 16 & $45-90$ & $5-10$ & $48-96$ & $2-4$ \\
\hline 17 & $50-100$ & $0-0$ & $49-98$ & $1-2$ \\
\hline 18 & $49-98$ & $1-2$ & $48-96$ & $2-4$ \\
\hline 19 & $50-100$ & $0-0$ & $47-94$ & $3-6$ \\
\hline 20 & $49-98$ & $1-2$ & $35-70$ & $15-30$ \\
\hline Total & $976-97.6$ & $24-2.4$ & $924-92.4$ & $76-7.6$ \\
\hline
\end{tabular}

Table 2. Points scored in the test (number $-\mathrm{N}$ and percentage - \%)

\begin{tabular}{lllll}
\hline Points & Doctors & & \multicolumn{2}{l}{ Medical technicians/nurses } \\
\hline & $\mathrm{N}$ & $\%$ & $\mathrm{~N}$ & $\%$ \\
\hline 20 & 34 & 68 & 17 & 34 \\
\hline 19 & 10 & 20 & 8 & 16 \\
\hline 18 & 4 & 8 & 13 & 26 \\
\hline 17 & 2 & 4 & 9 & 2 \\
\hline 16 & & & 1 & 2 \\
\hline 15 & & & 1 & 2 \\
\hline 14 & $\mathbf{5 0}$ & $\mathbf{1 0 0}$ & $\mathbf{5 0}$ & $\mathbf{1 0 0}$ \\
\hline Total & & & & 1 \\
\hline
\end{tabular}

ing program, and their aim is for doctors and technicians / nurses to acquire new theoretical knowledge and practical skills. According to the Regulations on detailed conditions for conducting continuous education for healthcare workers and associates, (4) doctors and nurses/technicians "have the right and obligation to continuously monitor developments in medical science, nursing care and other relevant skills, as well as other relevant sciences, and to develop themselves professionally in order to maintain and improve the quality of their work". BEMS accredits its courses, including the BLS course, through the Health Council of Serbia (Article 5 of the Regulations). The course was designed for MDs and MTs working at BEMS, who take part in the management of SCA not only as part of the reanimation team, but also, very often, as eyewitnesses in the early stages of SCA, out of their workplace and 


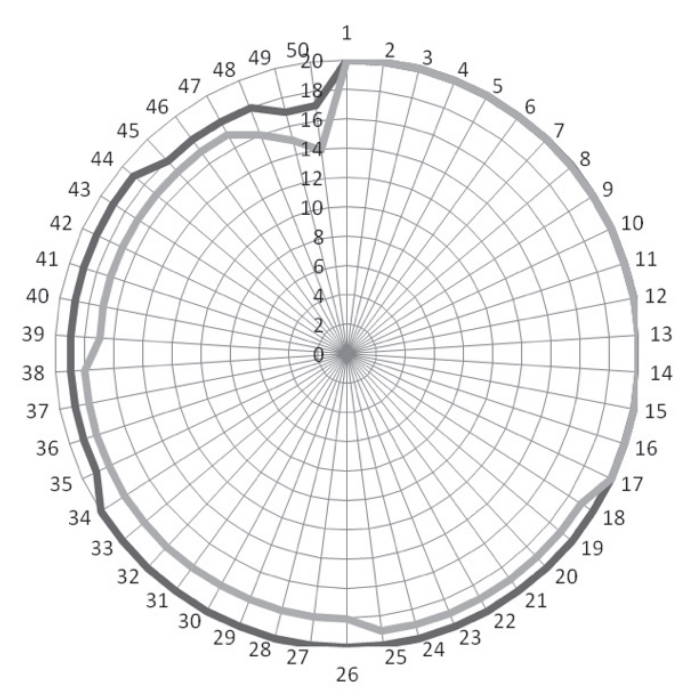

Figure1.Comparative overview of the total number of points scored in the test

Legend: black line-medical doctors; gray line - medical technicians; numbers 1-50 around

the circle $=$ participant number; numbers 1-20 inside circle $=$ question number

without medical equipment and instruments. Some studies show that as many as 100,000 human lives could be saved by early CPR. (5) Healthcare workers involved in emergency medicine need to be well aware of and monitor new developments in the field of CPR, which is a key factor in increasing the survival rate of these patients. The average numbers of correct answers in Group 1 (19.66) and Group 2 (18.91) show that doctors and nurses / technicians at BEMS are familiar with current guidelines in BLS.

Although the importance of qualifications of healthcare workers in the field of CPR is high, recent studies point to several problems. (6) The first problem stems from a lack of cognitive competence of doctors and nurses in this area. Many studies such as ours emphasize that the introduction of BLS training for doctors and nurses leads to significant improvements in BLS skills in the doctors' group. Unlike them, nurses do not have enough confidence and competence to independently conduct BLS. (7) However, Smith et al. state that none of the 30 MDs at their University Hospital acted in a standardized $\mathrm{ABC}$ (airway, breathing, circulation) procedure in the management of SCA and that only one of them acted in accordance with the guidelines for CPR. (8) It has been observed that doctorsspecialists maintain and revise their CPR skills poorly, (9) whereas young, recently graduated doctors do not have the proper skills to implement CPR according to cur-
(14) This technique changes the old traditional model of education whose motto was: "See one, Do one, Teach one"', into a new, modern and more successful model of learning:"See one, Practice many, Do one". The introduction of this approach will certainly contribute to better training of healthcare workers in EMS in the field of BLS.

The study showed a satisfactory level of knowledge among participants in both groups, but there was a statistically significant difference in the results achieved by doctors after completion of the BLS course. The results obtained justify the ambitions that all healthcare workers, regardless of their professional qualifications, should be trained in the implementation of BLS, both at their workplace and in the role of eyewitnesses of events.

\section{LIMITATIONS}

Our study has several limitations.

The main problem is the lack of translation of the current BLS guidelines into Serbian. As the official and native language in Serbia is Serbian, most of the respondents with insufficient command of foreign languages learn about current changes in BLS guidelines with delay.

Our study examined neither the length of the short and/or long-term maintenance of the acquired knowledge after training, nor did we determine variables that can affect the memorization or forgetfulness of BLS protocols.

Despite the existence of BLS courses for healthcare professionals throughout Serbia, there is still no clear consensus or common standard for this extremely important aspect of education.

It was also impossible to find out whether the participants of this study had a chance to implement BLS measures in the early phases of SCA, as witnesses, outside their workplace after the training. 


\section{APPENDIX 1.}

\section{TEST QUESTIONS WITH CORRECT ANSWERS (bolded)}

1. How do we approach an unconscious person?
a.) from the side
b.) from the head
c.) there is no rule

2. What is determined by the initial examination of the patient?
a.) patient's gende
b.) the injury
c.) state of consciousness, airway patency, breathing, pulse

3. What is the method used for checking the state of consciousness?
a.) look, listen, fee
b.) shake and call loudly
c.) Heimlich maneuver

4. What is the method used for opening the airway in an unconscious person who is not injured?
a.) triple grip
b.) tilt head back, raise chin
c.) slightly elevated legs

5. How long does the breathing assessment take in an unconscious person?

a.) up to 2 minutes b.) up to 10 minutes $\quad$ c.) up to 10 seconds

6. We start with chest compression:
a.) if the person is unconscious
b.) if the person is not breathing

c.) if the person is unconscious, not breathing, not coughing, not moving and there is no pulse

7. The correct spot for performing chest compression during resuscitation of an adult person is:
a.) 2 fingers below the intramamillary line
b.) middle of the chest c.) the tip of the sternum

8. In $C P R$ for adults the ratio of compression and ventilation in reanimation is:
a.) 15 compressions : 2 breaths
b.) 2 breaths : 30 compressions
c.) 30 compressions : 2 breaths

9. Removal of an obstructing foreign body in the airway of a conscious adult is done by:
a.) giving an abdominal thrust, halfway between the navel and the sternum
b.) pressing on the sternum
c.) pressing on the abdomen, at the height of the navel

10. During CPR the patient should be:

a.) Lying with a pillow under their head b.) lying on their back and on a hard surface c.) remain as we found them

11. When should we call for an ambulance if the person is unconscious?
a.) after the initial examination
b.) when you find out they are badly injured
c.) immediately

12. What should we do if the person is unconscious but breathing normally?
a.) start CPR
b.) place them in the coma position
c.) spray them with cold water

13. The sequence of procedures in starting resuscitation in an adult is:

a.) checking consciousness, checking and maintaining a clear airway, checking breathing 5 initial ventilations, 15 compressions : 2 ventilations, 1 minute of CPR 15:2, calling the emergency, CPR 15:2

b.) checking breathing, opening the airway, 2 ventilations, 30 compressions, calling the emergency

c.) checking consciousness, checking and opening the airway, checking breathing and pulse, calling the emergency service, 30 compressions on the breast bone : 2 ventilations

14. Which of the following are basic reanimation measures? (three correct answers)

a.) endotracheal intubation b.) chest compression c.) ventilation d.) drug administration e) opening the airway

15. Methods of relieving the airway from backward tongue displacement (three correct answers):

a.) tilt the head back, raise the chin b.) triple grip c.) coma position d.) Heimlich maneuver

16. Methods of artificial respiration in basic life support are: (three correct answers)

a.) mouth to mouth $\quad$ b.) nose to nose $c$.) mouth to mouth and nose d.) mouth to nose

17. The correct spot for compressions in adults is:
a.) middle of the chest
b.) top of the breast bone
c.) middle of the breast bone

18. The number of compressions (per minute) in CPR for adults is:
a.) 10
b.) from 100 to 120 c.) $60-80$ 
19. Is it enough that a person is unconscious to start CPR?

$\begin{array}{lll}\text { a.) YES } & \text { b.) } \mathrm{NO}\end{array}$

20. The ratio of breast bone compressions and ventilations in CPR in adults is always 2:30, regardless of the number of reanimators:

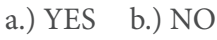

\section{REFERENCES}

1. Perkins G, Handleyc A, Koster R, Castréne M, Smytha M, Olasveengeng T, et al. on behalf of the Adult basic life support and automated external defibrillation section Collaborators. European Resuscitation Council Guidelines for Resuscitation 2015 Section 2. Adult basic life support and automated external defibrillation. Resuscitation 2015;95:81-99.

2. Jensen ML, Lippert F, Hesselfeldt R, Rasmussen MB, Mogensen SS, Jensen MK, et al.The significance of clinical experience on learning outcome from resuscitation training - a randomized controlled study. Resuscitation 2009;80:238-43.

3. Greif R, Lockey SA, Conaghanc P, Lippert A, De Vries W, Monsieurs GK, et al. European Resuscitation Council Guidelines for Resuscitation 2015 Section 10. Education and implementation of resuscitation. Resuscitation 2015;95:288-301.

4. Ordinance on Closer Conditions for the Implementation of Continuous Education for Health Workers and Health Associates - "Official Gazette of RS”, No. 2/2011, 23/2016. Available at: http:// www.zdravstvenisavetsrbije.gov.rs/dokumenta/zakoni/PravilnikOBlizimUslovimaZaSprovodenjeKontinuiraneEdukacije.pdf. Accessed August 16, 2017.

5. Pavlović A. Kardiopulmonalna reanimacija odraslih. In: Kalezić N, editor. Inicijalni tretman urgentnih stanja u medicini, Inicijalni tretman urgentnih stanja u medicini, 2nd ed. Beograd: Medicinski fakultet, 2016, p. 225-77.

6. Hunyadi-Antičević S. Analiza čimbenika koji utječu na osposobljavanje polaznika organiziranog programa trajnog usavršavanja iz područja reanimacije, [disertacija]. Zagreb: Medicinski fakultet Sveučilišta u Zagrebu, 2011.

7. Castle N, Garton H, Kenward G. Confidence vs competence: basic life support of health professionals. Br J Nurs 2007;16:664-6.

8. Smith J, Ryan K, Phelan D, McCarroll M. Cardiopulmonary resuscitation skills in non consultant hospital doctors - the Irish experience. Ir J Med Sci1993;162:405-7.

9. Broster S, Cornwell L, Kaptoge S, Kelsall W. Review of resuscitation training amongst consultants and middle grade paediatricians. Resuscitation 2007;74:495-9.

10. Jensen ML, Hesselfeldt R, Rasmussen MB, Mogensen SS, Frost T, Jensen MK, et al. Newly graduated doctors' competence in managing cardiopulmonary arrests assessed using a standardized Advanced Life Support (ALS) assessment. Resuscitation 2008;77:63-8.

11. Yakel ME. Retention of cardiopulmonary resuscitation skills among nursing personnel: what makes the difference? Heart Lung1989;18:520-5.

12. Hulme J, Perkins GD, Baldock C, Mac Namara A. Use of advanced life support skills. Resuscitation 2003;58:59-63.

13. Terzi B, Polat Ş and Sönmez DD. Evaluation of Basic Life Support Training Program Provided for Nurses in A University Hospital. IJRMHS 2017;6(6):70-6.

14. Pavlović A, Trpković S, Kalezić N. Edukacija zdravstvenih radnika u zbrinjavanju urgentnih stanja u medicini - simulaciona medicina. In: Kalezić N, editor. Inicijalni tretman urgentnih stanja u medicini, 2nd ed. Beograd: Medicinski fakultet, 2016, p. 939-69. 